ORIGINAL ARTICLE

\title{
The model of psychological safety of a soldier's personality
}

\author{
Ihor Prykhodko \\ National Academy of the National Guard of Ukraine, Kharkiv, Ukraine
}

\section{BACKGROUND}

From 2014 to the present, Ukrainian military personnel have been fighting in Eastern Ukraine against illegal armed formations of separatists. The resulting combat stress negatively affects servicemen's mental health status. This study aimed to examine the factor structure of a scale to assess the psychological safety of a soldier's personality (PSSP), taking into account changes in the conditions of military service to improve the professional and psychological training of military personnel.

\section{PARTICIPANTS AND PROCEDURE}

The study involved 118 officers of the National Guard of Ukraine. The semantic differential method, expert judgment, and exploratory factor analysis were used to determine the factor structure of the PSSP.

\section{RESULTS}

The PSSP model to maintain combat readiness in daily activities includes four components: "Moral and commu- nicative", "Motivational and volitional", "Value and meaning of life" and "Inner comfort". For activities in extreme conditions (during combat deployment), the personality potential of four structural components is used: "Moral and volitional regulation", "Coping strategies", "Value and meaning of life" and "Post-traumatic growth/regression".

\section{CONCLUSIONS}

The PSSP model consists of four components that have different content depending on the conditions for performance of professional tasks by military personnel. It is advisable to use the obtained results of the content of the PSSP model in the development of professional and psychological training programs for the purposeful formation of the resilience of military personnel, taking into account the conditions of their activities.

KEY WORDS

security; military personnel; military service, combat readiness; extreme conditions

CORResPonding AUthor - Prof. Ihor Prykhodko, National Academy of the National Guard of Ukraine, Zakhysnykiv

Ukrainy Square 3, 61001 Kharkiv, Ukraine, e-mail: prikhodko1966@ukr.net

AUthors' CONTRIBUtion - A: Study design - B: Data collection - C: Statistical analysis · D: Data interpretation .

E: Manuscript preparation · F: Literature search · G: Funds collection

TO CITE THIS ARTICLE - Prykhodko, I. (2022). The model of psychological safety of a soldier's personality. Current Issues

in Personality Psychology, 10(2), 112-122.

RECEIVED 14.03.2021 · REVIEWED 15.04.2021 · ACCEPTED 25.07.2021 · PUBLISHED 21.09.2021 


\section{BACKGROUND}

As a result of local armed conflicts, emergencies of a technogenic or socio-political nature, the number of people who have experienced mental trauma is increasing (Krasnyanskaya \& Tylets, 2015). The psychological consequences of such situations are often more significant in their socio-psychological impact than the events themselves (Blinov, 2018). Concerns about personal safety are also the major cause of mental disorders, such as anxiety, phobia, depression, and post-traumatic stress disorder (PTSD) (Zheng et al., 2016).

The term "psychological safety" was introduced to the organizational sciences a half-century ago by Schein and Bennis (1965), who stated that psychological safety reduces perceived threats, removes barriers to change, and allows employees to grow, learn, contribute, and perform effectively in a rapidly changing world. Kahn (1990) suggested that psychological safety was a condition necessary for people to feel attachments to and engagement in their work roles. He defined it as "feeling able to show and employ one's self without fear of negative consequences to self-image, status, or career" (Kahn, 1990, p. 708). Later Edmondson $(1999,2004)$ proposed a definition of psychological safety as being able to present one's opinions without the fear of being judged or facing negative consequences from the people around them. The researcher also defined the construct of team psychological safety as "a shared belief held by members of a team that the team is safe for interpersonal risktaking and models the effects of team psychological safety and team efficacy together on learning and performance in organizational work teams" (Edmondson, 1999, p. 350). Indeed, these conceptualizations of the psychological safety construct converge around a single, unifying principle: the importance of creating a workplace environment in which perceptions of interpersonal risk are minimized (Frazier et al., 2017).

After defining the basic principles of the concept, numerous studies of psychological safety were carried out at the individual (personality), team, and organizational levels (Newman et al., 2017). At the individual (personality) level, psychological safety mainly deals with a person's feeling where they feel free from anxiety and fear and are well versed with their needs (Ming et al., 2015). For teams, psychological safety is a key determinant of high-quality communication, trust, decision-making, similar beliefs, and values, which improves team performance and plays an important role within the workplace (Edmondson \& Lei, 2014). Psychological safety at an organizational level is related to the environment at the workplace which reflects trust and openness in the organization (Ming et al., 2015).

Most of the psychological safety research has been conducted in the civil sector, namely with the partici- pation of employees involved in economics, management, and industry. However, psychological safety also plays a particularly vital role in high-risk work contexts, such as military service (Boe, 2015; Chu et al., 2016; Nindl et al., 2018), law enforcement (Gong et al., 2020), and healthcare (e.g., O’Donovan et al., 2020). The nature of these professions can be extreme and can lead to adverse health consequences. Börjesson et al. (2015) point out that extreme situations with risks to the health and life of military personnel are integral components of combat deployment (CD). Almost every soldier experiences combat stress under these conditions (Pols \& Oak, 2007; Prykhodko et al., 2020). The impact of combat stress on military personnel begins before direct contact with the enemy and continues until they leave the $\mathrm{CD}$ zone (Figley \& Nash, 2007). The constant threat to health and life, changes in the combat situation, severe and prolonged psychological loads that exceed the limits of human capabilities, the loss of comrades, and brutal violence against the enemy can significantly affect the mental health and personality of combatants (Prykhodko et al., 2019). One study found that in the first year of combat in Eastern Ukraine, $75-80 \%$ of military personnel developed short-term acute stress reactions, accompanied by partial or complete loss of combat effectiveness (Blinov, 2018).

However, military professional activity does not always take place in extreme conditions. It consists of two components: maintaining combat readiness (MCR) in everyday non-combat conditions and serving in CD (hostilities, battle drills). The main goal of activity in everyday conditions is the professional training of military personnel for CD. The professional activity of military personnel in $\mathrm{CD}$ requires a soldier to be ready to effectively carry out any combat missions while preserving life, health, and material resources as much as possible.

Until 2014, the main direction in the reform of the Armed Forces of Ukraine (AFU) was the reduction of both military personnel and weapons and military equipment. Therefore, with the outbreak of hostilities in Eastern Ukraine, in which servicemembers of the AFU and the National Guard of Ukraine (NGU) took part against illegal armed formations of separatists supported by the Russian Federation, there were certain problems. In the first years of the war, most of the Ukrainian military personnel had no combat experience, since after the Second World War no military operations were carried out on the territory of Ukraine. At the time of the outbreak of the armed conflict, it was revealed that the existing level of professional and psychological training of Ukrainian military personnel was not sufficient to conduct large-scale, nonstandard, asymmetric hostilities (Kokun et al., 2020). According to Blinov (2018), 80-90\% of Ukrainian combatants showed signs of combat stress reaction, $25 \%$ of combatants subsequently developed PTSD of varying 
severity, $20 \%$ of combatants showed some symptoms of maladaptation reactions, and $27 \%$ of military personnel had anxiety, depression, and hostility.

This study aimed to examine the factor structure of a scale to assess the psychological safety of a soldier's personality (PSSP), taking into account changes in the conditions of military service to improve the professional and psychological training of military personnel. It was hypothesized that the conditions for fulfilling professional tasks for MCR in daily activities and during $\mathrm{CD}$ of a unit will have different effects on the PSSP.

\section{PARTICIPANTS AND PROCEDURE}

\section{PARTICIPANTS}

In the study, 118 officers of NGU took part as experts: 24 psychologists, 31 researchers and lecturers of higher military academies, 38 commanders of NGU units, and 25 postgraduate students. All experts were male, had higher education (graduated from higher military (civil) educational institutions), and the age of the experts was from 31 to 49 years. The experts were officers (they had military ranks from captain to colonel); postgraduate students (prior to master's degree) and unit commanders served in positions ranging from Company Commander to Brigade Commander. All military psychologists had a psychological education (bachelors, masters) and served in positions ranging from a Psychologist of a Separately Deployed Battalion to the Head of the Psychological Support Service of the Main Directorate of NGU. Researchers (in positions from Senior Researcher to Head of the Laboratory) worked in the Research Laboratory for Psychological Support of Service and Combat Activities of NGU. Lecturers and teachers (all Ph.D. degree, in positions from Senior Teacher to Head of the Department) taught future military psychologists at the National Academy of the National Guard of Ukraine.

The selection of experts was carried out according to the following: successful professional activity and authority among colleagues (on the annual certification, the average score for the assessment of professional activity is more than 4.5 on a 5-point Likert scale); psychological, military, or legal education; more than 10 years of professional experience in the specialty; experience of activity in combat (extreme) conditions $(100 \%$ of them took part in hostilities in Eastern Ukraine).

\section{PROCEDURE}

The semantic differential method (Osgood, 1952; Serkin, 2008; Stoklasa et al., 2019) was used to quantitatively and qualitatively determine the investigated
PSSP construct. The semantic differential is a method of constructing individual or group semantic spaces (rating scales) to assess attitudes and beliefs of the investigated object, construct, or concept. Osgood's theory of the semantic differential was an application of his more general attempt to measure the semantics or meaning of words, particularly adjectives, and their referent concepts (Serkin, 2008). Osgood and colleagues (1957) performed a factor analysis of large collections of semantic differential scales and found three recurring attitudes that people use to evaluate words and phrases: evaluation, potency, and activity. Evaluation loads highest on the adjective pair 'good-bad'. The 'strong-weak' adjective pair defined the potency factor. The adjective pair 'active-passive' defined the activity factor. These three dimensions of affective meaning were found to be cross-cultural universals in a study of dozens of cultures (Osgood et al., 1957; Serkin, 2008; Stoklasa et al., 2019).

The created questionnaire (seven points' semantic differential scales) was used to measure opinions, beliefs, and attitudes about the PSSP construct. The experts were asked to choose where one's position lies, on a scale between two polar features (for example: "safe-dangerous", "tranquil-anxious" or "optimistic-pessimistic"). The study of the structure of the PSSP construct was carried out using paper questionnaires. The survey was implemented in Ukrainian. Exploratory factor analysis was used to examine the factor structure of the PSSP construct.

The construction of the questionnaire was carried out in six stages: 1) study, theoretical description, and definition of relevant features (indicators) of PSSP for the development of the questionnaire; 2) highlighting the first set of features with the help of a group of experts; 3) cutting off insignificant features and defining the second set of features (the decision was made to include only items with factor loadings of .60 or higher); 4) processing of results and construction of a working version of the semantic differential; 5) selection of the main features and formation of the final version (Appendix) of the questionnaire (consisting of 35 features and their antonyms) separately for MCR and during $\mathrm{CD} ; 6$ ) the use of exploratory factor analysis (the valence of the obtained score: the higher the factor load of the feature (indicator), the more significant it was for compliance with the PSSP construct).

The same participants assessed the content of features in the PSSP construct in different conditions of professional activity of military personnel: for MCR and during $\mathrm{CD}$. With the help of the questionnaire developed by us and the use of exploratory factor analysis, the content of the PSSP construct was determined.

All procedures followed were in accordance with the ethical standards of the responsible committee on human experimentation (institutional and national) and with the Helsinki Declaration of 1975, as revised in 2000 . The study was approved by the 
Research Ethics Committee at the National Academy of National Guard of Ukraine (protocol no. 2 dated 09/11/2020).

\section{DATA ANALYSIS}

The obtained data were subjected to the exploratory factor analysis procedure (Howard, 2016; Watkins, 2018). This made it possible to determine the factor matrix of the grouping of personality characteristics related to the PSSP construct separately for MCR, and separately for during CD. Exploratory factor analysis of matrices was carried out using the extraction method (principal component analysis) and the rotation method (Varimax with Kaiser normalization). The statistical analysis of the results of the study was carried out using the program SPSS 22.0.

\section{RESULTS}

The results of exploratory factor analysis indicated a four-factor structure of the PSSP model for MCR, describing $75.56 \%$ of the variance of features (Table 1). The first factor (component) contained $25.13 \%$ of the variance of features; the second factor contained $24.38 \%$ of the variance; the third factor contained $13.61 \%$ of the variance, and the fourth factor contained $12.44 \%$ of the variance. The decision was made to include only items with factor loadings of .60 or higher, used as a criterion for the level of significance, which made it possible to avoid the inclusion of personality characteristics (indicators) with a low factor load in the factors (Howard, 2016; Serkin, 2008).

The content of the first factor was determined by high factor loading with the features "moral", "sociable", "benevolent", "communicable", "responsible", "politeness", "organized". Taking into account such a combination of characteristics containing moral and communicative personality traits, the first component of the PSSP model for MCR was named "Moral and communicative".

The content of the second factor was determined by high factor loading with the features "optimistic", "active", "purposeful", "self-confident", "hardy", "initiative", "controlling" and "innovative". The combination of these features can be attributed to the peculiarities of setting and achieving goals: developed goal-setting, the intensity in setting goals, and flexibility in correcting them. Such a combination of personality traits was proposed in the theory of Ilyin (2013), which defines volition as goal-setting, voluntary motivation. Therefore, the second component of the model was named "Motivational and volitional".

High factor loading determined the third factor with the features "brave", "socially responsible", "involved in events" and "cheerful". It has been interpret- ed as a component of the PSSP, in which responsibility and involvement in events are characteristics of the meaningfulness of life included in the personality potential proposed by Leontev (2011). This component of the model was named "Value and meaning of life".

High factor loading determined the fourth factor with the features "reliable", "safe" and "protected". Its content reflected the personality traits of a soldier, who assesses combat readiness in daily activities as safe and one's mental status as comfortable (Prykhodko, 2013). Therefore, this component of the model was named "Inner comfort".

At the next stage of the study, the analysis of the results obtained using the questionnaire, was carried out to identify the components of the PSSP model during $\mathrm{CD}$ associated with a direct risk to health and life for military personnel. The results of exploratory factor analysis, covering $72.81 \%$ of the total variance of features, make it possible to reveal that the PSSP model during $\mathrm{MCR}$ and $\mathrm{CD}$ requires different personal characteristics in order to feel safe (Table 2).

The content of the first factor of the PSSP model during $\mathrm{CD}$ is determined by the presence of high factor loading with personality traits that reflected the volitional sphere and norms of relations. In contrast to the previous model, in this factor structure, the regulation and norms of relations were supplemented by indicators related to the volitional sphere of the personality and intellect. These are features that reflect the volitional sphere of the personality: "purposeful", "independent", "self-confident", "controlling", "organized", "autonomous", and "risky". This factor also contains features that characterize the moral regulation, norms of relations, and the peculiarities of interaction with others: "benevolent", "socially responsible", "politeness", "honesty", "responsible", "moral", "keenness", "modesty", and "communicable". Correlation with the indicator "highly intelligent (creative)" also testifies to the norms of relations. Thus, this component was named "Moral and volitional regulation".

The content of the second factor was determined by high factor loading with personality characteristics reflecting resistance to stressful influences ("psychologically resilient", "hardy", and "stress-resistant"); feelings of psychological well-being ("safe") and the means of achieving it ("adaptive"). Thus, this component combines the factors "Motivational and volitional" and "Inner comfort" of the PSSP models for MCR. We named this combination of personal characteristics "Coping strategies" for overcoming stressful situations.

The content of the third factor was determined by high factor loading with the variables "initiative", "active", "involved in events", "innovative". Unlike a similar component of the previous model, this one includes more variables that describe the proactive personality. However, if a person feels a lack of meaning in life, then it is possible for him to develop 
Table 1

Factorial matrix of grouping of personality characteristics related to the construct "psychological safety of a soldier's personality" for maintaining combat readiness in daily activities, rotated component matrix ${ }^{a}$

\begin{tabular}{|c|c|c|c|c|}
\hline \multirow{2}{*}{$\begin{array}{l}\text { Personality characteristics } \\
\text { (indicators) }\end{array}$} & \multicolumn{4}{|c|}{ Factors (Components) } \\
\hline & $1(25.13 \%)$ & $2(24.38 \%)$ & $3(13.61 \%)$ & $4(12.44 \%)$ \\
\hline Safe & .23 & -.03 & .21 & .91 \\
\hline Reliable & .15 & .07 & .16 & .92 \\
\hline Brave & -.12 & .10 & .80 & .33 \\
\hline Protected & -.11 & .42 & .16 & .79 \\
\hline Cheerful & .05 & .30 & .64 & .14 \\
\hline Hardy & -.10 & .74 & .28 & -.05 \\
\hline Involved in events & .18 & .04 & .79 & .06 \\
\hline Controlling & .22 & .70 & .03 & .16 \\
\hline Innovative & .27 & .66 & .43 & -.05 \\
\hline Active & .27 & .77 & .28 & .14 \\
\hline Initiative & .44 & .74 & .16 & -.05 \\
\hline Optimistic & .14 & .85 & .31 & .15 \\
\hline Socially responsible & .34 & .22 & .80 & .09 \\
\hline Politeness & .71 & .26 & .14 & .15 \\
\hline Purposeful & .45 & .77 & -.03 & .04 \\
\hline Self-confident & .27 & .75 & -.13 & .32 \\
\hline Responsible & .76 & .44 & -.04 & -.06 \\
\hline Organized & .70 & .45 & .06 & .07 \\
\hline Sociable & .89 & .11 & .06 & -.08 \\
\hline Benevolent & .86 & .18 & .12 & .17 \\
\hline Communicable & .84 & .22 & .20 & -.01 \\
\hline Moral & .89 & .01 & .10 & .25 \\
\hline
\end{tabular}

Note. Extraction method: principal component analysis. Rotation method: Varimax with Kaiser normalization. ${ }^{\text {Retation converged }}$ in 6 iterations.

an existential crisis, refusal to manifest activity in self-realization, further struggle, and manifest selfdestruction. The acquisition of the meaning of life after a person's stay in combat (extreme) conditions of activity becomes a locus that inspires and gives strength to overcome any obstacles (Kokun et al., 2020). This component, as in the previous model, was also called "Value and meaning of life".

The content of the fourth factor was determined by high factor loading with the variables "leading a healthy lifestyle" and "optimistic". Experiencing extreme (combat) situations is often associated with a strong tension of personality resources. A positive exit from it can lead to a decrease in their tension, the appearance of positive emotions, relaxation, "a feel- ing of happiness that I remained alive" (Prykhodko et al., 2020). Positive emotions can lead to the consolidation of the obtained changes, a positive vector of personality development, and also can lead to post-traumatic growth (Tedeschi \& Calhoun, 2004). However, in a negative scenario of the development of events, if the extreme situation does not have a positive ending, the person can focus on negative feelings and experience despair. If ordinary negative emotions, although they are unpleasant, nevertheless contribute to change, then the experience of despair can lead to the abandonment of existing forms of interaction with the environment. This can leads to post-traumatic regression of personality development (Prykhodko, 2013). Therefore, this component 
Table 2

Factorial matrix of grouping of personality characteristics related to the construct "psychological safety of a soldier's personality" during combat deployment, rotated component matrix ${ }^{a}$

\begin{tabular}{|c|c|c|c|c|}
\hline \multirow{2}{*}{$\begin{array}{l}\text { Personality characteristics } \\
\text { (indicators) }\end{array}$} & \multicolumn{4}{|c|}{ Factors (Components) } \\
\hline & $1(36.98 \%)$ & $2(13.89 \%)$ & $3(15.47 \%)$ & $4(6.47 \%)$ \\
\hline Safe & -.20 & .70 & .51 & .10 \\
\hline Brave & -.12 & .10 & .80 & .33 \\
\hline Hardy & .12 & .72 & .25 & .18 \\
\hline Involved in events & -.04 & .14 & .68 & .13 \\
\hline Controlling & .83 & .12 & .36 & -.09 \\
\hline Risky & .65 & .06 & .59 & -.07 \\
\hline Psychologically resilient & -.10 & .84 & -.03 & .10 \\
\hline Adaptive & -.03 & .71 & -.03 & .34 \\
\hline Stress-resistant & -.27 & .67 & -.01 & -.17 \\
\hline Highly intelligent (creative) & .68 & -.08 & .55 & -.10 \\
\hline Innovative & .51 & .04 & .64 & .20 \\
\hline Active & .24 & .24 & .71 & -.23 \\
\hline Initiative & .45 & -.03 & .78 & -.17 \\
\hline Optimistic & .06 & .26 & .44 & .60 \\
\hline Socially responsible & .71 & .56 & .01 & .15 \\
\hline Leading a healthy lifestyle & .02 & -.13 & .17 & .83 \\
\hline Politeness & .82 & .21 & -.23 & .39 \\
\hline Keenness & .87 & .22 & -.10 & .34 \\
\hline Honesty & .86 & .18 & -.35 & .13 \\
\hline Modesty & .78 & .08 & -.50 & .32 \\
\hline Independent & .86 & -.30 & -.21 & -.07 \\
\hline Purposeful & .94 & .09 & -.07 & -.09 \\
\hline Self-confident & .85 & .29 & .21 & -.04 \\
\hline Autonomous & .77 & .32 & .03 & .09 \\
\hline Responsible & .86 & .20 & -.25 & .05 \\
\hline Organized & .79 & -.22 & .34 & .17 \\
\hline Benevolent & .91 & .05 & -.13 & .17 \\
\hline Communicable & .82 & .04 & -.08 & -.10 \\
\hline Moral & .86 & .28 & -.21 & -.06 \\
\hline
\end{tabular}

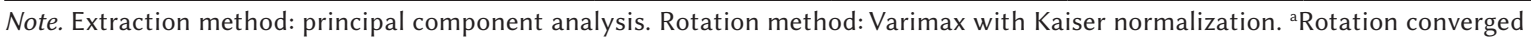
in 8 iterations.

of the model was named "Post-traumatic growth/regression" of personality development.

Thus, almost all the main personality characteristics (indicators) of the four components of the PSSP model for MCR are also presented in the four-factor PSSP model during CD (Table 3). Their regrouping took place with the emergence of three new components. The "Value and meaning of life" component remained unchanged, only supplemented by several characteristics that describe an active life position in realizing the meaning obtained. The "Moral and communicative" component of the PSSP model for 


\section{Figure 1}

The structure of the PSSP model for maintaining combat readiness in daily activities and during combat deployment

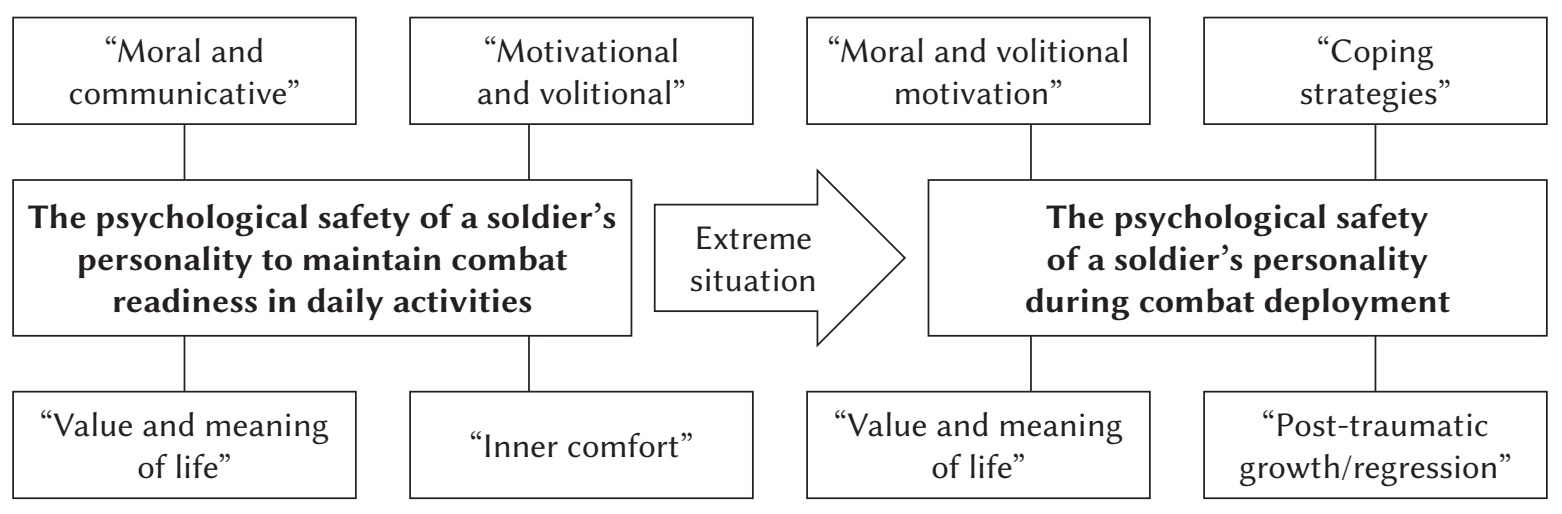

MCR, in contrast, faded into the background in the context of a real vital threat: the preservation of life and health has become of paramount importance.

The results obtained allow us to confirm the hypothesis that the conditions for fulfilling professional tasks for MCR in daily activities and during CD will have different effects on the PSSP. The structure of the PSSP model for MCR in daily activities and during $\mathrm{CD}$ is shown in Figure 1.

\section{DISCUSSION}

As a result of the study carried out, a model of PSSP was created, taking into account changes in the conditions of military service to improve the professional and psychological training of military personnel. The PSSP model consists of four components that have different content depending on the conditions for performance of professional tasks by military personnel.

The latent variable of the "Moral and communicative" component of the PSSP model for MCR in daily activities is to implement acceptable interaction with the social environment since the main task for a person is to ensure safety. Its solution depends on communicative traits and adherence to social norms, which at the level of interpersonal behavior are represented by moral norms. Social norms structure social space, make it usually predictable, and this helps to reduce tension in relationships, and makes it possible to predict the results of the interaction. According to Ben-Shalom et al. (2005), King (2006), and Siebold (2007), good communication and cohesion within the unit contribute to the development of mutual respect, companionship, openness, and trust, consideration of interests of each other, and mutual assistance. Compliance with social norms and developed communication skills allow a person to avoid unwanted conditions and create favorable conditions for self-development. Our findings are supported by the results of studies by Bartone (2006), Ben-Shalom et al. (2005), King (2006), and Siebold (2007), in which it was found that the main prerequisites for the effective operation of a military collective in extreme situations are good communication, combat coordination, and cohesion.

The latent variable of the "Motivational and volitional" component is the use of the chosen strategy of personality self-realization in different conditions of activity. This requires a flexible and intensive goalsetting mechanism, as well as developed volitional traits to achieve goals. This allows one to create an operational plan of action for the implementation of personal motives, taking into account external (social, physical) conditions and one's own resources. Volitional traits assist in the implementation of the developed action plan, transferring it from a potential state to an actual one. Their combination provides self-confidence, in the correctness of their actions, which, according to Myrseth et al. (2020), is the basis for maintaining the professional activity of military personnel in conditions that provide for the exercise of choice, "struggle of motives". Our results are confirmed in the studies of Heckhausen (1991) and Shamlyan (2020), which determined that the necessary signs of volitional behavior of a personality are the obligatory presence of a conscious goal, tangible obstacles, and the implementation of efforts to overcome them.

The content of this component of the PSSP is similar to the concept of hardiness, which is a necessary psychological characteristic for the professional activity of military personnel. Bartone (2006) investigated changes of resilience in conditions of militaryoperational stress in servicemen and the effect of leaders on the resilience of subordinates. The author found that if military leaders have the potential to 
build their own hardiness, then that is also a resource for increasing resilience to the stress of their subordinates. The findings of other researchers show that the totality of the personality characteristics that make up this component can provide the mobilization of the personality's volitional efforts and can encourage combat activities (Boe, 2015; Nindl et al., 2018). According to Pols and Oak (2007), volitional efforts ensure a person's ability to maintain resilience in various circumstances of activity and are a prerequisite for ensuring the high efficiency of professional activities of military personnel. In contrast to the PSSP model for MCR in the PSSP model for $\mathrm{CD}$, an increase in the role of will and intelligence indicates the deployment of control over the process of interaction with others, which under normal conditions is automated and minimized. Thus, the novelty and complexity of an extreme situation require more careful control when using norms and algorithms of actions. This stimulates a person to use productive coping strategies for the implementation of professional activities in combat (extreme) conditions.

The latent variable of the "Value and meaning of life" component is the formation of "the 'axis of consciousness', which can ensure the sequence of selfrealization of the personality in ordinary conditions and the resilience of military personnel in extreme situations" (Prykhodko, 2013, p. 178). To do this, a person must have a system of attitudes towards oneself, one's professional activity, and others, based on the values and meanings that determine the vector of personality development. The value sphere of the personality allows one to more gently experience the impact of trauma and determines the vector of development: post-traumatic growth (Ramos \& Leal, 2013; Tedeschi \& Calhoun, 2004) or post-traumatic regression (Prykhodko, 2013). Each life failure frustration is considered by an individual from the point of view of its influence on the ability to implement the chosen life strategy, which makes it possible to rise above a number of problems that cause negative experiences and their devaluation. Nevertheless, extreme situations in which an existential threat arises can lead to an overestimation of values and meanings, and also their significance in the value structure of a personality. Our findings are supported by the results of studies by Zimmermann et al. (2014), who found that a strong and conscious system of personality values can help protect military personnel from the development of depression and PTSD after the end of hostilities. The greatest significance of this component of the PSSP model shows that reflection, control, awareness of one's place in society, and the meaning of one's existence, is the most important moment for survival in an extreme situation, and is also the basis for accomplishing a feat (Prykhodko, 2013).

The latent variable of the "Inner comfort" component is to achieve internal consistency of the person- ality, the relative stability of behavior, interpretation of experience, and the formation of expectations. As a result of its functioning, an individual experiences a feeling of satisfaction or dissatisfaction with oneself, with one's life: negative experiences lead to changes in the direction of activity, positive ones reinforce the acquired experience, "conserve" the structure of PSSP (Prykhodko, 2013). If this contradicts the existing ideas of the soldier about oneself, one's life, then the mechanisms of psychological defense are triggered, helping the individual to interpret the traumatic experience or to deny it. Our findings are consistent with a study exploring the role of career adaptability, feedback environment, and goal-self concordance in improving the psychological safety of the Chinese police (Gong et al., 2020).

\section{STRENGTHS AND LIMITATIONS}

A major strength of this study, which is based on the theory of psychological safety, is that it is the first to explore the PSSP using a personalized approach in defining a psychologically protected personality. Nevertheless, it is important to note a few limitations related to the study. First, only 118 participants took part in the PSSP model content study. Such a limited number of participants was chosen due to such criteria as participation in hostilities during the deployment in Eastern Ukraine. Secondly, all study participants were included in four heterogeneous groups (psychologists, researchers and lecturers of higher military academies, commanders of NGU units, and postgraduate students), which made it difficult to determine the consistency of their opinions. Third, the sample consisted entirely of men. Finally, the training of military service members in different national armies for deployment and the conduct of hostilities may have differences, which could also affect the content of the PSSP model. However, the results of this study represent new steps in establishing the psychological safety of a soldier's personality as a construct, but additional conceptual and empirical work is needed to refine and extend the implications of the construct before firm conclusions can be drawn.

\section{CONCLUSIONS}

As a result of the study, a PSSP model was created that takes into account changes in the conditions of military service of military personnel. In the PSSP model, the leading role is assigned to the adaptive resources of the personality, which allows the effectiveness of the professional activity of military personnel to be maintained in any condition. The "Value and meaning of life" component of the PSSP model is the most significant for the activities of military personnel in 
combat conditions, where reflection, control, and the meaning of existence are the leading characteristics for survival in an extreme situation and the basis for accomplishing a feat. To maintain combat readiness in daily activities, the personality potential of four structural and functional components is used: "Moral and communicative", "Motivational and volitional", "Value and meaning of life" and "Inner comfort". For activities in extreme conditions (during combat deployment), the personality potential of four structural and functional components is used: "Moral and volitional regulation", "Coping strategies", "Value and meaning of life" and "Post-traumatic growth/regression". It is advisable to use the obtained results of the content of the PSSP model in the development of professional and psychological training programs for the purposeful development of the resilience of military personnel, taking into account the conditions of their activities.

\section{References}

Bartone, P. T. (2006). Resilience under military operational stress: Can leaders influence hardiness? Military Psychology, 18, S131-S148. https://doi. org/10.1207/s15327876mp1803s_10

Ben-Shalom, U., Lehrer, Z., \& Ben-Ari, E. (2005). Cohesion during military operations. Armed Forces \& Society, 32, 63-79. https://doi.org/10.1177/ 0095327 X05277888

Blinov, O. (2018). Combat stress and results of its empirical study. Psychological Journal, 4, 9-22. https://doi.org/10.31108/2018vol12iss2pp9-22

Boe, O. (2015). Building resilience: The role of character strengths in the selection and education of military leaders. International Journal of Emergency Mental Health and Human Resilience, 17, 714-716.

Börjesson, M., Österberg, J., \& Enander, A. (2015). Risk propensity within the military: a study of Swedish officers and soldiers. Journal of Risk Research, 18, 55-68. https://doi.org/10.1080/13669877. 2013.879489

Chu, C., Stanley, I. H., Hom, M. A., Lim, I. C., \& Joiner, T. E. (2016). Deployment, mental health problems, suicidality, and use of mental health services among military personnel. Military Behavioral Health, 4, 243-250. https://doi.org/10.1080/216357 81.2016.1153533

Edmondson, A. (1999). Psychological safety and learning behavior in work teams. Administrative Science Quarterly, 44, 350-383. httpa://doi.org/ $10.2307 / 2666999$

Edmondson, A. C. (2004). Psychological safety, trust, and learning in organizations: a group-level lens. In R. M. Kramer \& K. S. Cook (Eds.), Trust and distrust in organizations: Dilemmas and approaches (pp. 239-272). Russell Sage Foundation.
Edmondson, A. C., \& Lei, Z. (2014). Psychological safety: The history, renaissance, and future of an interpersonal construct. Annual Review of Organizational Psychology and Organizational Behavior, 1, 23-43. https://doi.org/10.1146/annurev-orgpsych-031413-091305

Figley, C. R., \& Nash, W. P. (2007). Combat stress injury: Theory, research, and management. Routledge/ Taylor \& Francis Group.

Frazier, M. L., Fainshmidt, S., Klinger, R. L., Pezeshkan, A., \& Vracheva, V. (2017). Psychological safety: a meta-analytic review and extension. Personnel Psychology, 70, 113-165. https://doi. org/10.1111/peps. 12183

Gong, Z., Yang, J., Gilal, F. G., Van Swol, L. M., \& Yin, K. (2020). Repairing police psychological safety: The role of career adaptability, feedback environment, and goal-self concordance based on the conservation of resources theory. SAGE Open, 10. https://doi.org/10.1177/2158244020919510

Howard, M. C. (2016). A review of exploratory factor analysis decisions and overview of current practices: What we are doing and how can we improve? International Journal of Human-Computer Interaction, 32, 51-62. https://doi.org/10.1080/10447318. 2015.1087664

Heckhausen, H. (1991). Motivation and action. Springer. Ilyin, E. P. (2013). Psihologiya voli [Psychology of volition]. Piter.

Kahn, W. A. (1990). Psychological conditions of personal engagement and disengagement at work. Academy of Management Journal, 33, 692-724. https://doi.org/10.2307/256287

King, A. (2006). The word of command. Armed Forces \& Society, 32, 493-512. https://doi.org/10. 1177/0095327X05283041

Kokun, O., Agayev, N., Pischko, I., \& Stasiuk, V. (2020). Characteristic impacts of combat stressors on posttraumatic stress disorder in Ukrainian military personnel who participated in the armed conflict in Eastern Ukraine. International Journal of Psychology \& Psychological Therapy, 20, 315-326.

Krasnyanskaya, T. M., \& Tylets V. G. (2015). Psikhologicheskie resursy bezopasnosti lichnosti s razlichnym opytom ekstremal'nosti [Psychological resources of the security in individuals with various extreme experiences]. Medical-Biological and Socio-Psychological Problems of Safety in Emergency Situations, 2, 100-107.

Leontev, D. A. (2011). Lichnostnyiy potentsial: struktura i diagnostika [Personality potential: structure and diagnosis]. Smysl.

Ming, C., Xiaoying, G., Huizhen, Z., \& Bin, R. (2015). A review on psychological safety: Concepts, measurements, antecedents and consequences variables. Proceedings of the 2015 International Conference on Social Science and Technology Education. https://doi.org/10.2991/icsste-15.2015.118 
Myrseth, H., Hystad, S. W., Säfvenbom, R., \& Olsen, O. K. (2020). Perception of specific military skills - the impact of perfectionism and self-efficacy. Journal of Military Studies, 9, 34-48. https:// doi.org/10.2478/jms-2018-0002

Newman, A., Donohue, R., \& Eva, N. (2017). Psychological safety: a systematic review of the literature. Human Resource Management Review, 27, 521-535. https://doi.org/10.1016/j.hrmr.2017.01.001

Nindl, B. C., Billing, D. C., Drain, J. R., Beckner, M. E., Greeves, J., Groeller, H., Teien, H. K., Marcora, S., Moffitt, A., Reilly, T., Taylor, N., Young, A. J., \& Friedl, K. E. (2018). Perspectives on resilience for military readiness and preparedness: Report of an international military physiology roundtable. Journal of Science and Medicine in Sport, 21, 11161124. https://doi.org/10.1016/j.jsams.2018.05.005

O’Donovan, R., Van Dun, D., \& McAuliffe, E. (2020). Measuring psychological safety in healthcare teams: Developing an observational measure to complement survey methods. BMC Medical Research Methodology, 20, 203. https://doi.org/10.1186/ s12874-020-01066-z

Osgood, C. E. (1952). The nature and measurement of meaning. Psychological Bulletin, 49, 197-237. https://doi.org/10.1037/h0055737

Osgood, C. E., Suci, G., \& Tannenbaum, P. (1957). The measurement of meaning. University of Illinois Press.

Pols, H., \& Oak, S. (2007). War and military mental health. American Journal of Public Health, 97, 21322142. https://doi.org/10.2105/AJPH.2006.090910

Prykhodko, I. I. (2013). Zasady psykholohichnoi bezpeky personalu ekstremalnykh vydiv diialnosti [Principles of psychological safety of personnel of extreme activities]. National Academy of the National Guard of Ukraine.

Prykhodko, I., Matsehora, Y., Bielai, S., Hunbin, K., \& Kalashchenko, S. (2019). Classification of coping strategies influencing mental health of military personnel having different combat experience. Georgian Medical News, 12, 130-135.

Prykhodko, I. I., Bielai, S. V., Hrynzovskyi, A. M., Zhelaho, A. M., Hodlevskyi, S. O., \& Kalashchenko, S. I. (2020). Medical and psychological aspects of safety and adaptation of military personnel to extreme conditions. Wiadomości Lekarskie, 73, 679-683. https://doi.org/10.36740/WLek202004110

Ramos, C., \& Leal, I. (2013). Posttraumatic growth in the aftermath of trauma: a literature review about related factors and application contexts. Psychology, Community \& Health, 2, 43-54. https://doi. org/10.5964/pch.v2i1.39

Schein, E. H., \& Bennis, W. G. (1965). Personal and organizational change through group methods: the laboratory approach. Wiley.

Serkin, V. P. (2008). Metody psihologii subektivnoj semantiki i psihosemantiki [Methods of psychology of subjective semantics and psycho-semantics]. Psichea.

Shamlyan, K. (2020). Volitional organization of personality as a subject of empirical research. Journal of Education Culture and Society, 6, 257-267. https://doi.org/10.15503/jecs20152.257.267

Siebold, G. L. (2007). The essence of military group cohesion. Armed Forces \& Society, 33, 286-295. https://doi.org/10.1177/0095327X06294173

Stoklasa, J., Talášek, T., \& Stoklasová, J. (2019). Semantic differential for the twenty-first century: Scale relevance and uncertainty entering the semantic space. Quality \& Quantity, 53, 435-448. https://doi.org/10.1007/s11135-018-0762-1

Tedeschi, R. G., \& Calhoun, L. G. (2004). Posttraumatic growth: Conceptual foundations and empirical evidence. Psychological Inquiry, 15, 1-18. https://doi.org/10.1207/s15327965pli1501_01

Watkins, M. W. (2018). Exploratory factor analysis: a guide to best practice. Journal of Black Psychology, 44, 219-246. https://doi.org/10.1177/0095798 418771807

Zheng, Z., Gu, S., Lei, Y., Lu, S., Wang, W., Li, Y., \& Wang, F. (2016). Safety needs mediate stressful events induced mental disorders. Neural Plasticity, 2016, 1-6. https://doi.org/10.1155/2016/8058093

Zimmermann, P., Firnkes, S., Kowalski, J. T., Backus, J., Siegel, S., Willmund, G., \& Maercker, A. (2014). Personal values in soldiers after military deployment: Associations with mental health and resilience. European Journal of Psychotraumatology, 5, 22939. https://doi.org/10.3402/ejpt.v5.22939 
APPENDIX

\section{QUESTIONNAIRE FOR THE STUDY OF THE CONSTRUCT "PSYCHOLOGICAL SAFETY OF A SOLDIER'S PERSONALITY"}

Instruction: Dear Expert! We ask you to take part in the study of the construct "psychological safety of a serviceman's personality”. Evaluate the significance of the features (indicators) that a psychologically protected soldier should have. Pay attention to how to work with the form. Each line of the form is a scale (1 234567 ). Pick one value (circle or cross out) between two opposite poles. The closer your assessment is to this pole, the more pronounced this feature (indicator) is and the less pronounced the opposite pole will be.

\begin{tabular}{|c|c|c|}
\hline Features (indicators) & Number & Features (indicators) \\
\hline Safe & 1234567 & Dangerous \\
\hline Reliable & 1234567 & Threatening \\
\hline Brave & 1234567 & Cowardly \\
\hline Protected & 1234567 & Defenseless \\
\hline Cheerful & 1234567 & Apathetic \\
\hline Hardy & 1234567 & Unstable \\
\hline Involved in events & 1234567 & Indifferent \\
\hline Controlling & 1234567 & Uncontrollable \\
\hline Risky & 1234567 & Conservative \\
\hline Psychologically resilient & 1234567 & Psychologically unstable \\
\hline Adaptive & 1234567 & Maladaptive \\
\hline Stress-resistant & 1234567 & Instable to stress \\
\hline Tranquil & 1234567 & Anxious \\
\hline Highly intelligent (creative) & 1234567 & Non-intellectual (ignorant) \\
\hline Innovative & 1234567 & Inactive \\
\hline Active & 1234567 & Passive \\
\hline Initiative & 1234567 & Inert \\
\hline Optimistic & 1234567 & Pessimistic \\
\hline Socially responsible & 1234567 & Socially irresponsible \\
\hline Leading a healthy lifestyle & 1234567 & $\begin{array}{l}\text { Having bad habits (drug addiction, } \\
\text { alcoholism, etc.) }\end{array}$ \\
\hline Mentally healthy & 1234567 & Mentally ill \\
\hline Politeness & 1234567 & Coarseness \\
\hline Keenness & 1234567 & Callousness \\
\hline Honesty & 1234567 & Dishonor \\
\hline Modesty & 1234567 & Shamelessness \\
\hline Independent & 1234567 & Dependent \\
\hline Purposeful & 1234567 & Purposeless \\
\hline Self-confident & 1234567 & Unconfident \\
\hline Autonomous & 1234567 & Subordinate \\
\hline Responsible & 1234567 & Irresponsible \\
\hline Organized & 1234567 & Unorganized \\
\hline Sociable & 1234567 & Sullen \\
\hline Benevolent & 1234567 & Hostile \\
\hline Communicable & 1234567 & Uncommunicative \\
\hline Moral & 1234567 & Immoral \\
\hline
\end{tabular}

